\title{
Development of Specially Reinforced Magnesium Composites Prepared by Squeeze Casting Process
}

\author{
Akshansh Mishra $^{1}$, Devarrishi Dixit ${ }^{2}$ \\ ${ }^{1}$ Centre for Artificial Intelligent Manufacturing Systems, Stir Research Technologies, India \\ ${ }^{2}$ Department of Material Science, Christian-Albrechts-Universität zu Kiel \\ ${ }^{1}$ Orcid id: https://orcid.org/0000-0003-4939-359X \\ ${ }^{2}$ Orcid id: https://orcid.org/0000-0002-5126-6154
}

\begin{abstract}
A wide range of opportunities in the field of automotive and structural applications are being offered by Magnesium matrix composites because of their enhanced mechanical properties. Magnesium alloys based Metal Matrix Composites (MMCs) are the best candidates for lightweight structural applications due to their improved creep properties. In the present study, three specimens of specially reinforced magnesium composites were manufactured by using the squeeze casting process. Specimen 1 has a composition of $7 \%$ aluminum alloy in addition to $1 \%$ zinc and the composition of reinforcement is Titanium Carbide $0.3 \%$ in addition to $1.5 \%$ Carbon nanotubes. Specimen 2 has a composition of $12 \%$ aluminum alloy in addition to $1 \%$ zinc and the composition of reinforcement is $2 \% B_{4} C$ in addition to $2 \%$ Carbon nanotubes. Specimen 3 has a composition of $14 \%$ aluminum alloy in addition to $1 \%$ zinc and the composition of reinforcement is $2 \% \mathrm{~B}_{4} \mathrm{C}$ in addition to $2 \%$ Carbon nanotubes. The mechanical properties analysis showed that specimen 2 has a higher hardness value in comparison to other manufactured specimens and it was also observed that specimen 2 possesses a higher tensile strength value in comparison to the other two specimens. Microstructure analysis shows that there was a uniform distribution of the reinforcements in the matrix. So it can be inferred that this uniform distribution causes higher hardness and higher tensile strength in the manufactured specimens.
\end{abstract}

Keywords: Squeeze Casting; Magnesium Matrix Composites; Carbon Nano Tubes (CNTs); Titanium Carbide.

\section{Introduction}

Metal Matrix Composites (MMCs) can be considered lightweight structural materials that were developed in the 1990s for meeting the requirements in aerospace applications [1-3]. They have strong potential to replace cast iron and other materials in brakes and engines due to their high strength to weight ratio, low density, high fatigue, wear and creep resistance, and at last high-temperature strength retention [4-5]. Magnesium and its alloys have attracted much attention in scientific development and as well as in various commercial applications because of their low density and high specific strength in comparison to other structural metals. In aerospace and automotive applications these properties order to reduce weight, greenhouse emission, and fuel consumption [6-8]. But due to their poor creep resistance behavior at high temperatures, the application of magnesium and its alloys are limited. So in order to overcome these limitations and to improve the properties, reinforcements are 
incorporated [9-10]. Dinaharan et al. [11] reinforced titanium particles $(0,7,14$, and 21 vol $\%)$ into an AZ31 magnesium alloy by friction stir processing method. The obtained results showed enhanced tensile strength and good ductility in the manufactured composite. Say et al. [12] investigated the corrosion resistance and mechanical properties of AZ91 and AZ61 magnesium matrix composites reinforced with $01,0.2$, and $0.5 \mathrm{wt} \%$ carbon nanotubes (CNTs). It was observed that with the increasing amount of carbon nanotubes, the strength of composites increases.

In recent work, the squeeze casting process has been used for fabricating the magnesiumbased Metal Matrix Composites (MMCs). In the next sections, the experimental procedure and results obtained will be further discussed.

\section{Material and Methods}

Firstly, the ingots of magnesium, aluminum, and zinc weighing in the range of 950 to 990 gram per specimen were taken for composing the matrix purpose. Secondly, the preheating of the ingot mixture consisting of magnesium, aluminum, and zinc is carried out to a temperature of 650 degrees celsius. Thirdly, carbon nanotubes powder with $B_{4} \mathrm{C}$ powder are added as reinforcements then the mixture is taken into an oven and is preheated to a temperature of 300 degrees celsius. After that, by using a funnel these mixtures are poured into a furnace where the mixture is subjected to a stirring process in order to enhance the homogenous nature in the mixture at a different rotation rate for a time period of 10 minutes. The furnace gate is then opened after the stirring process and through the runner molten composite is further transferred to squeeze die arrangement. At a pressure of 40.2 tonnes, compression is performed by the hydraulic press on the obtained composite inside the die. The cooling process is incurred on the composite for a time period of 10 minutes inside the die. After cooling, the fabricated composite is taken outside for carrying out the finishing and machining process. Figure 1 shows the specimen after casting and Figure 2 shows the specimen after finishing operation.

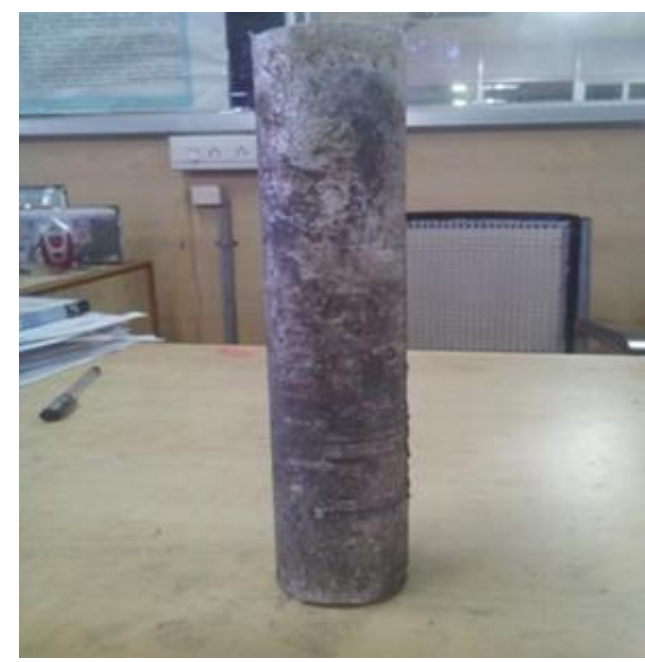

Figure 1. Specimen obtained after casting process 


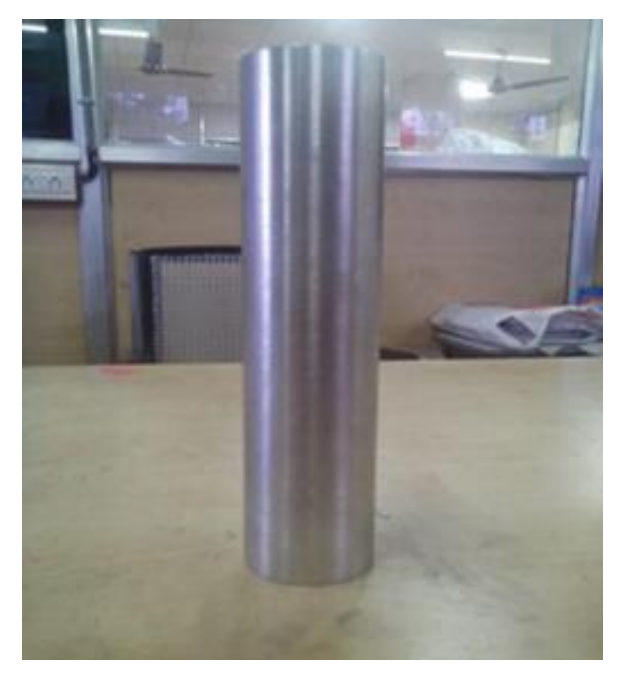

Figure 2. Specimen obtained after finishing process

Composition of fabricated three specimens is shown in Table 1.

Table 1. Composition of composite specimens in weight $\%$

\begin{tabular}{lllccc}
\hline $\begin{array}{l}\text { Specimen } \\
\text { Number }\end{array}$ & Al & Zn & TiC & $\boldsymbol{B}_{\mathbf{4}} \boldsymbol{C}$ & $\begin{array}{l}\text { Carbon } \\
\text { Nanotubes }\end{array}$ \\
\hline $\mathbf{1}$ & 7 & 1 & 0.3 & - & 1.5 \\
$\mathbf{2}$ & 12 & 1 & - & 2 & 2 \\
$\mathbf{3}$ & 14 & 1 & - & 2 & 2 \\
\hline
\end{tabular}

\section{Results and Discussion}

\subsection{Microstructure properties analysis}

For obtaining the clear grain boundaries in the microstructure a proper specimen preparation is needed. Polishing and etching are the two kinds of preparation that are subjected to these specimens as shown in Figure 3 and Figure 4.

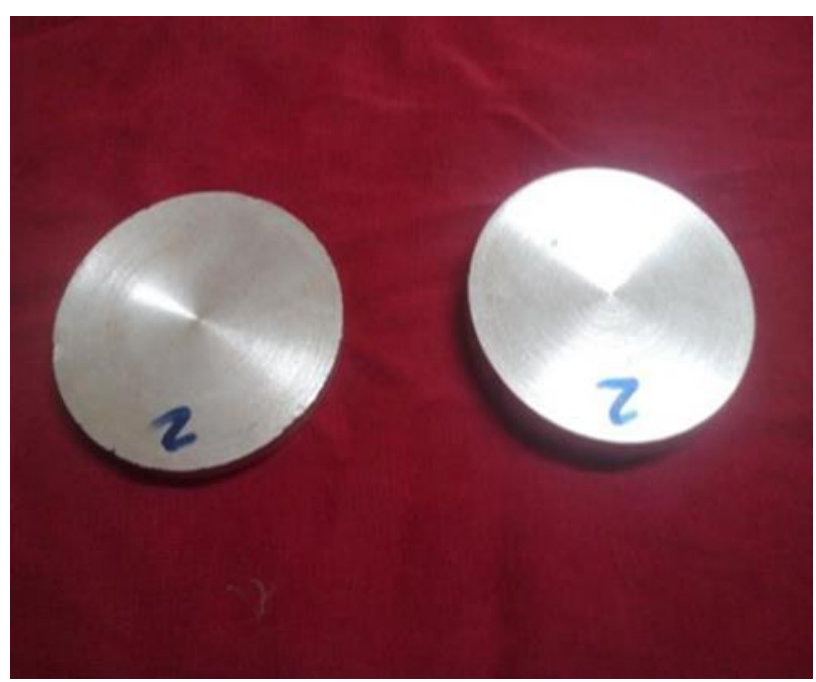


Figure 3. Non-etched and unpolished composite specimen

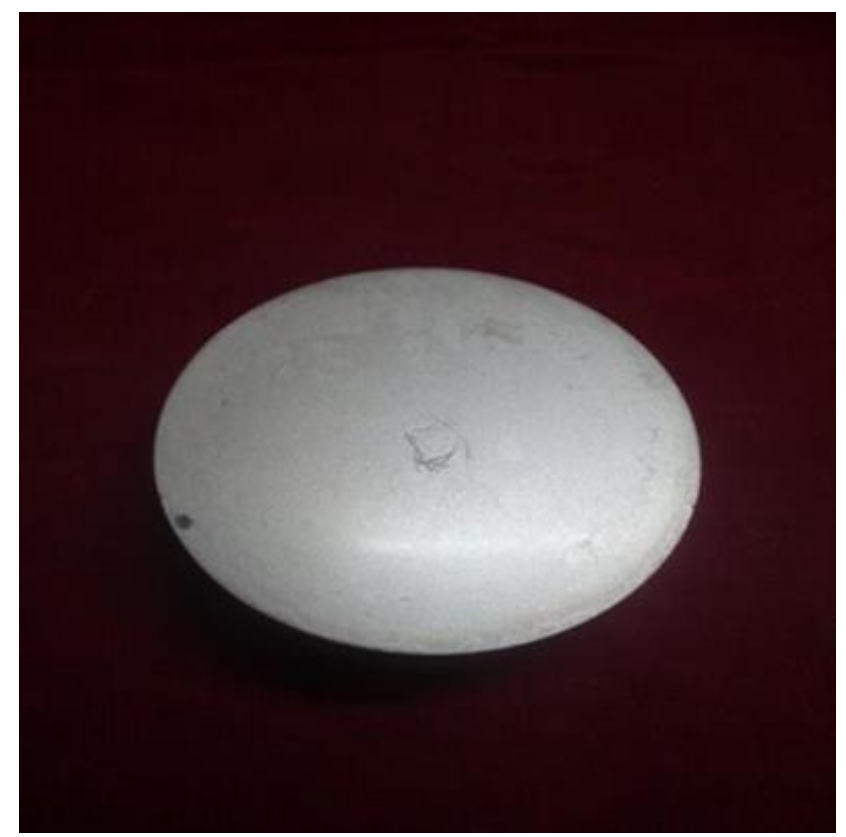

Figure 4. Etched and emery polished surface of composite specimen

The specimen surfaces may appear smooth to the human eyes but in reality, it consists of various scratches, irregularities, and grooves which happens when the specimen is subjected to various machining operations. So in order to increase the surface smoothness of the surface, polishing is done with different grades of emery paper such as 800, 1000, 1200, and 1500. For clear grain boundary observation, the etchant consisted of $92 \mathrm{ml}$ distilled water, 6 $\mathrm{ml}$ of nitric acid with $65 \%$ concentration, and $2 \mathrm{ml}$ of hydrofluoric acid with $40 \%$ concentration. The microstructures obtained for specimen 1, specimen 2 , and specimen 3 are shown in Figures 5-7.

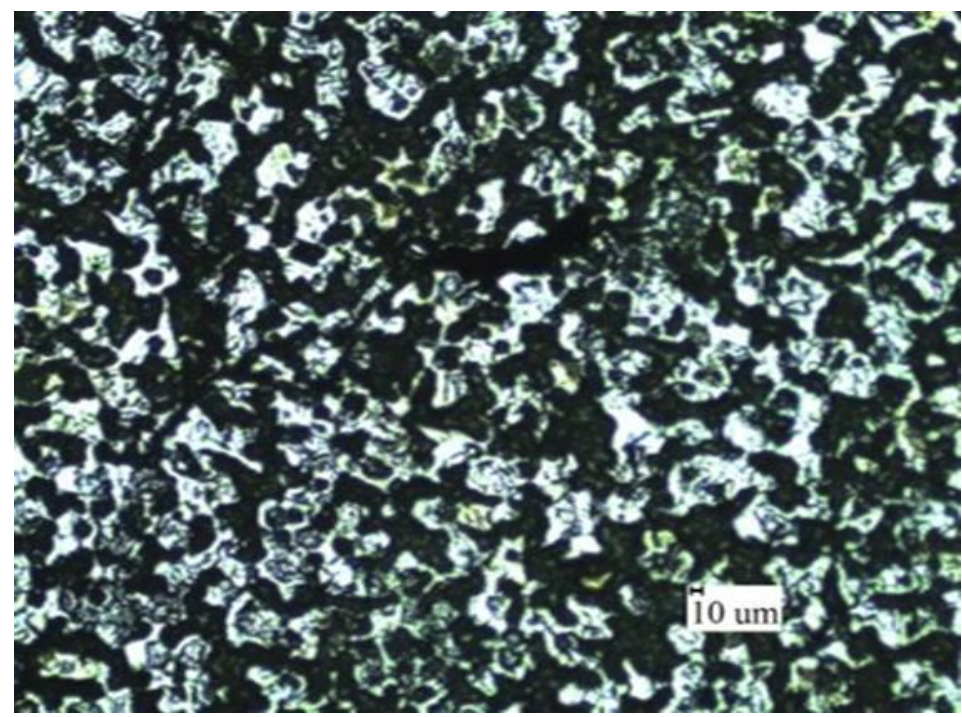


Figure 5. Microstructure of specimen 1 at the magnification of 100X.

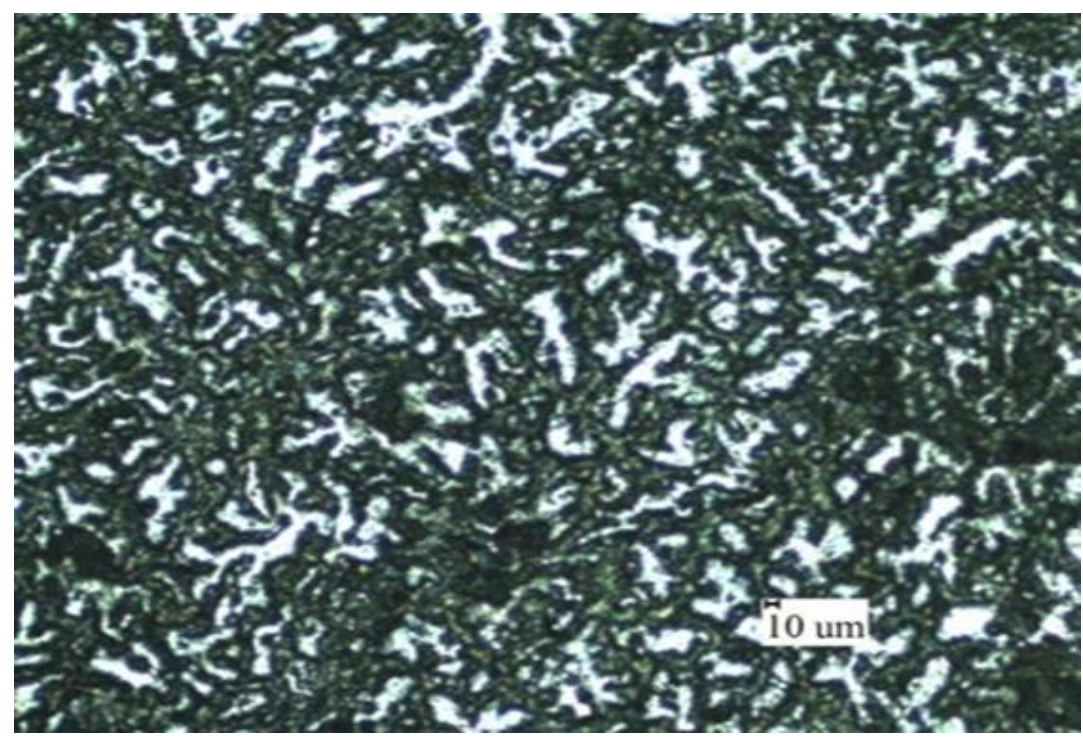

Figure 6. Microstructure of specimen 2 at the magnification of $100 \mathrm{X}$

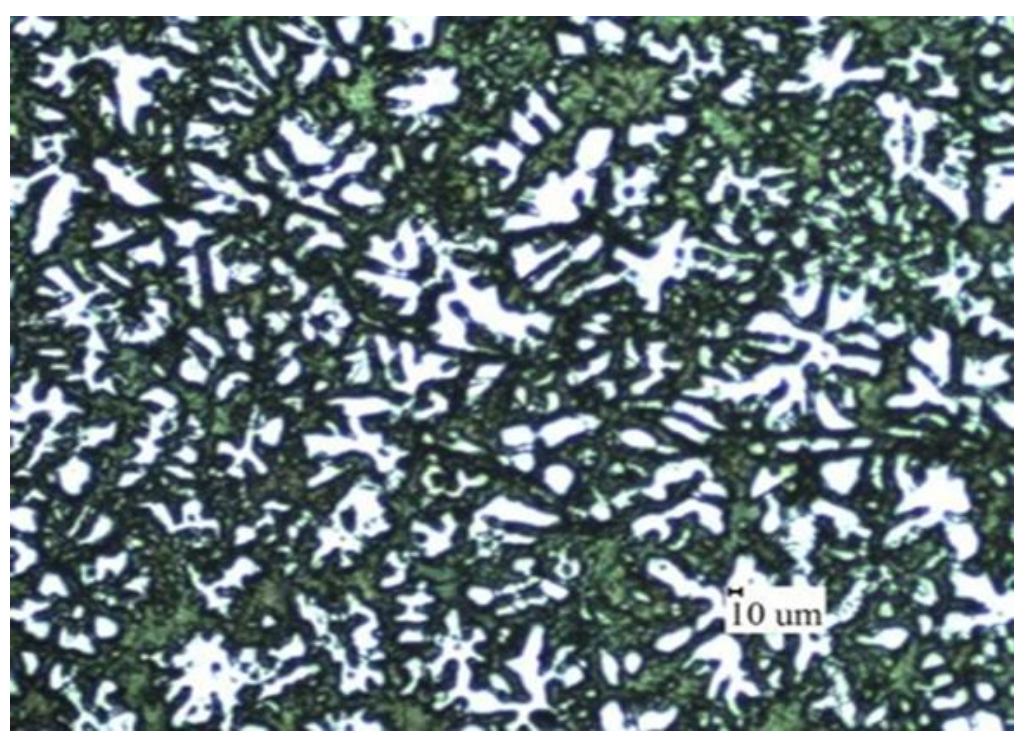

Figure 7. Microstructure of specimen 3 at the magnification of $100 \mathrm{X}$

From the microstructure analysis of specimen 1, it is observed that there was a non-uniform distribution of the reinforcement in the matrix. It is also observed that due to the existence of slipping between grain boundaries there is a formation of extremely coarse microstructure. From the microstructure analysis of specimen 2, it is observed that there is a uniform distribution of the reinforcement in the matrix and also might be due to less slip occurrence the formation of the microstructure is very fine in nature in comparison to the other two specimens. From the microstructure analysis of specimen 3, it is observed that the reinforcement distribution is slightly non-uniform in nature and it was also observed that in comparison to specimen 1 the microstructure obtained was fine but in comparison to specimen 2 the grain boundaries obtained are coarse due to occurrence of slipping between 
the grain boundaries. The microstructures obtained from SEM test for these three specimens are shown in Figure 8-10.

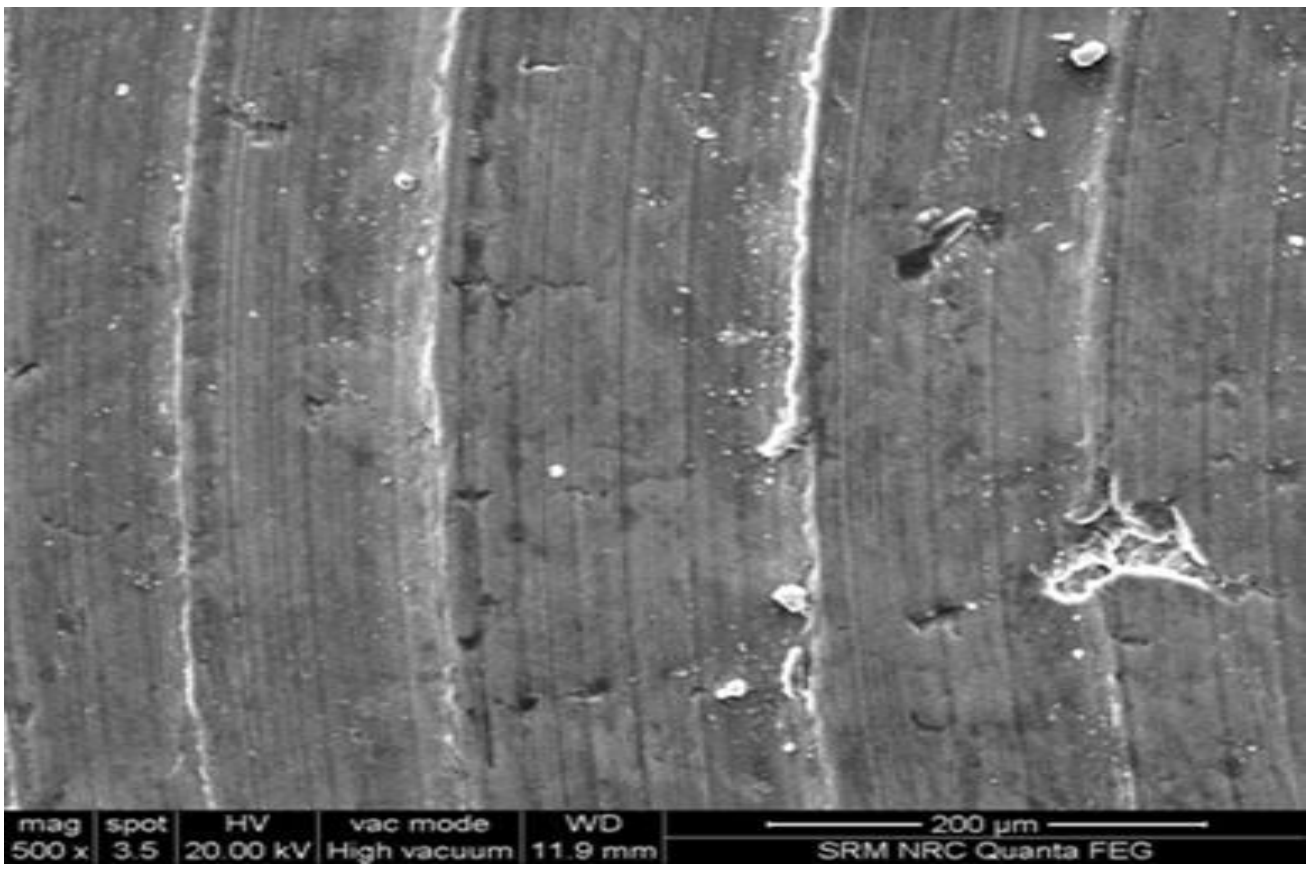

Figure 8. SEM microstructure of Specimen 1

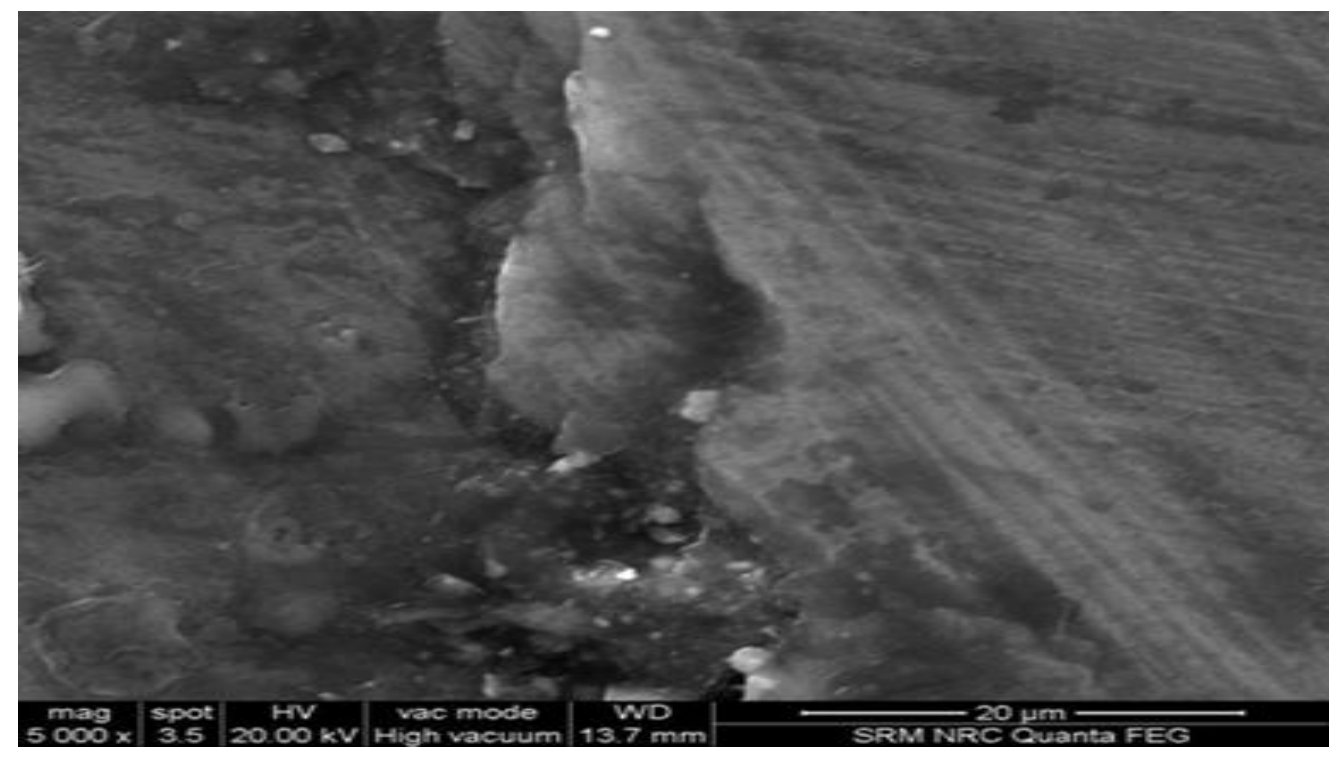

Figure 9. SEM microstructure of Specimen 2 


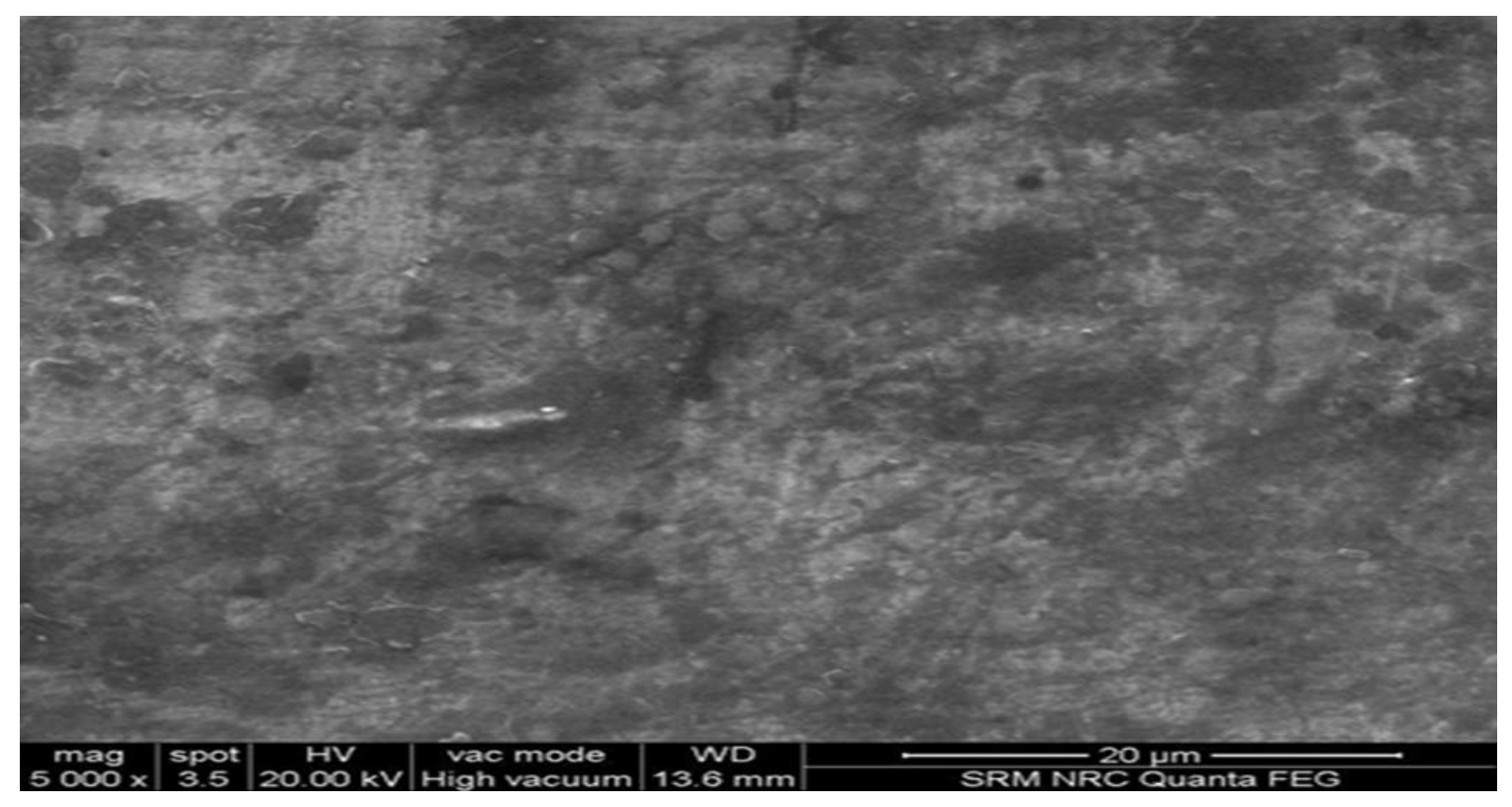

Figure 10. SEM microstructure of specimen 3

\subsection{Mechanical properties analysis}

Tensile test results for specimen 1, specimen 2 and specimen 3 are shown in Figure 11-13 and in Table 2-4.

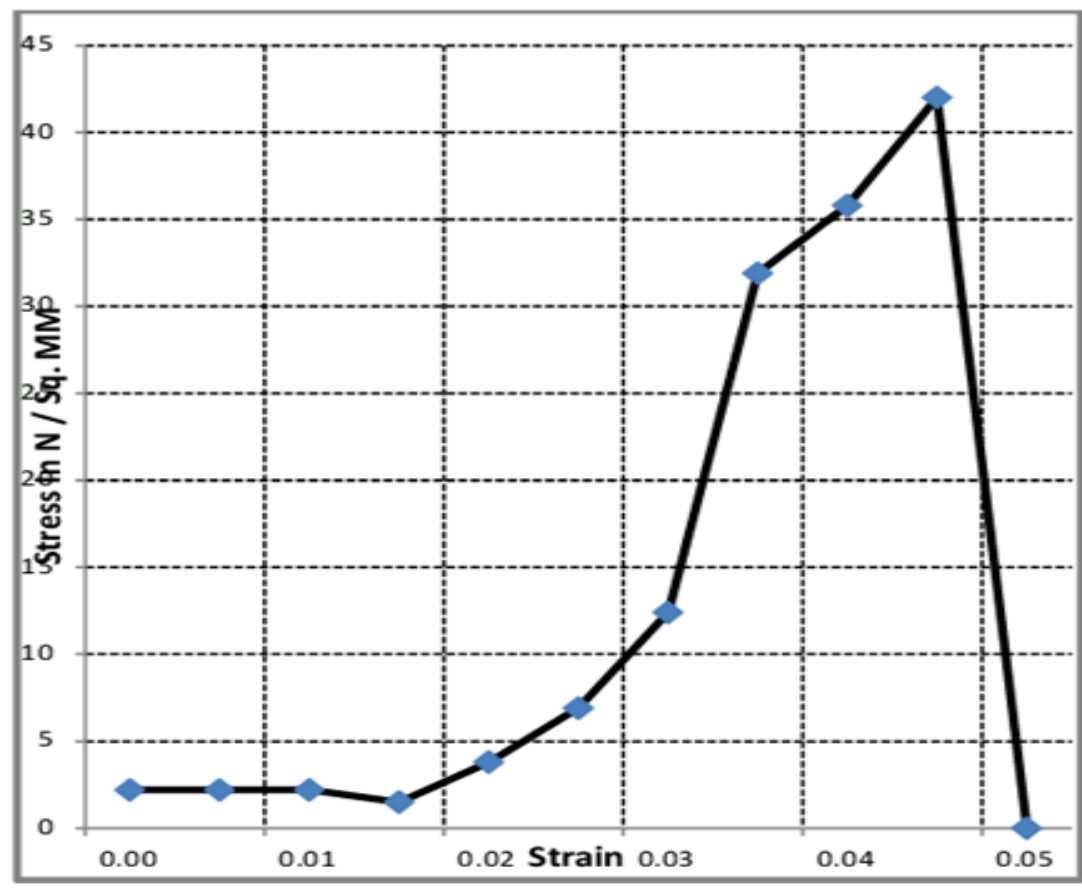

Figure 11. Tensile test graph plot of specimen 1 
Table 2. Tensile test result of specimen 1

\begin{tabular}{|ll}
\hline Part & TENSILE MG01 \\
\hline Material & MG01 GR \\
\hline Test Mode & Peak / Break \\
\hline High Limit & $20000 \mathrm{~N}$ \\
\hline Low Limit & $10 \mathrm{~N}$ \\
\hline Cross Sec Area & $12.56 \mathrm{Sq} \mathrm{mm}$ \\
\hline Sample Length & $20.0 \mathrm{~mm}$ \\
\hline $\begin{array}{l}\text { Selected Load } \\
\text { Cell }\end{array}$ & $20 \mathrm{kN}$ \\
\hline Test Speed & $5.0 \mathrm{~mm} / \mathrm{min}$ \\
\hline Peak Load & $528 \mathrm{~N}$ at length : $0.9 \mathrm{~mm}$ \\
\hline Break Load & $450 \mathrm{~N}$ at length : $1.0 \mathrm{~mm}$ \\
\hline Peak Disp & $4.5 \%$ \\
\hline Break Disp & $5.0 \%$ \\
\hline Ten/Cmp Stress & $42.0 \mathrm{~N} / \mathrm{Sq} \mathrm{mm}$ \\
\hline U.T.S. & $42.0 \mathrm{~N} / \mathrm{Sq} \mathrm{mm}$ \\
\hline
\end{tabular}

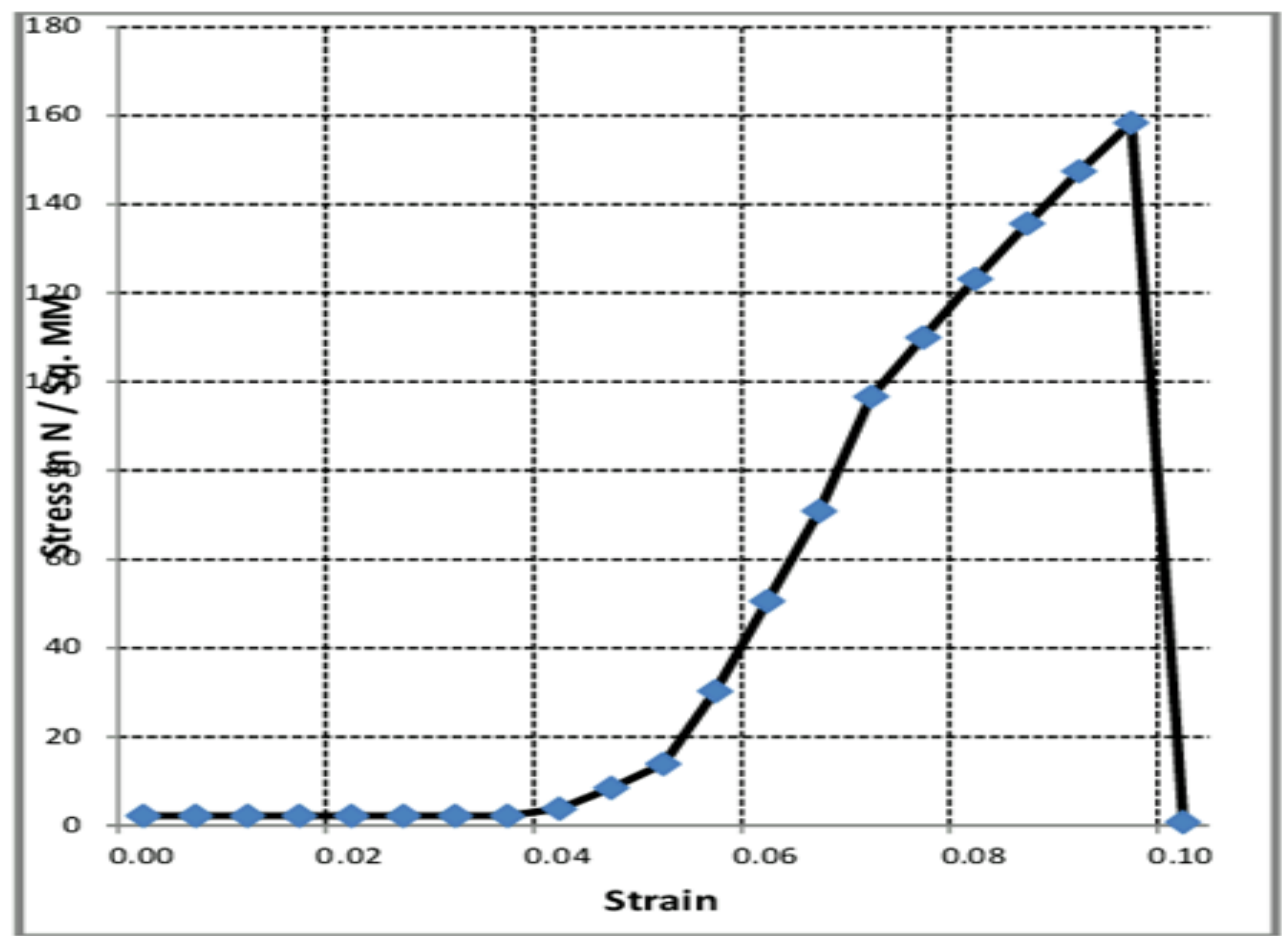

Figure 12. Tensile test graph plot of specimen 2 
Table 3. Tensile test result of specimen 2

\begin{tabular}{|ll|}
\hline Part & TENSILE MG02 \\
\hline Material & MG02 GR \\
\hline Test Mode & Peak / Break \\
\hline High Limit & $20000 \mathrm{~N}$ \\
\hline Low Limit & $10 \mathrm{~N}$ \\
\hline Cross Sec Area & $12.56 \mathrm{Sq}$ mm \\
\hline Sample Length & $20.0 \mathrm{~mm}$ \\
\hline Selected Load Cell & $20 \mathrm{kN}$ \\
\hline Test Speed & $5.0 \mathrm{~mm} / \mathrm{min}$ \\
\hline Peak Load & $1990 \mathrm{~N}$ at length: $1.9 \mathrm{~mm}$ \\
\hline Break Load & $1990 \mathrm{~N}$ at length : $1.9 \mathrm{~mm}$ \\
\hline Peak Disp & $9.5 \%$ \\
\hline Break Disp & $9.5 \%$ \\
\hline Ten/Cmp Stress & $158.4 \mathrm{~N} /$ Sq mm \\
\hline U.T.S. & $158.4 \mathrm{~N} /$ Sq mm \\
\hline
\end{tabular}

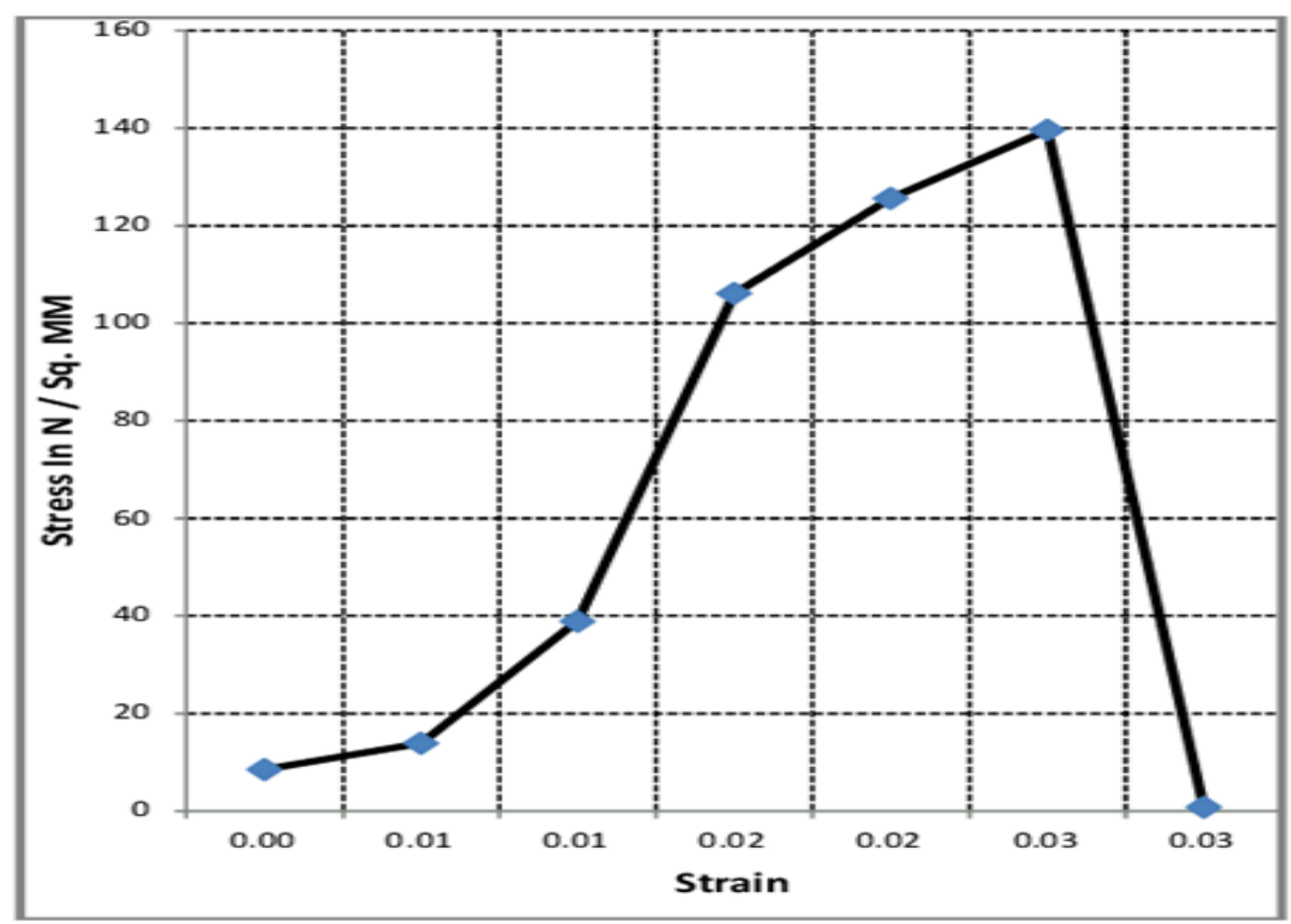

Figure 13. Tensile test graph plot of specimen 3 
Table 4. Tensile test result of specimen 3

\begin{tabular}{|ll|}
\hline Part & TENSILE MG03 \\
\hline Material & MG03 GR \\
\hline Test Mode & Peak / Break \\
\hline High Limit & $20000 \mathrm{~N}$ \\
\hline Low Limit & $10 \mathrm{~N}$ \\
\hline Cross Sec Area & $12.56 \mathrm{Sq} \mathrm{mm}$ \\
\hline Sample Length & $20.0 \mathrm{~mm}$ \\
\hline $\begin{array}{l}\text { Selected Load } \\
\text { Cell }\end{array}$ & $20 \mathrm{kN}$ \\
\hline Test Speed & $5.0 \mathrm{~mm} / \mathrm{min}$ \\
\hline Peak Load & $1754 \mathrm{~N}$ at length : $0.9 \mathrm{~mm}$ \\
\hline Break Load & $1754 \mathrm{~N}$ at length : $1.0 \mathrm{~mm}$ \\
\hline Peak Disp & $2.5 \%$ \\
\hline Break Disp & $2.5 \%$ \\
\hline Ten/Cmp Stress & $139.6 \mathrm{~N} / \mathrm{SQ} \mathrm{mm}$ \\
\hline U.T.S. & $139.6 \mathrm{~N} / \mathrm{SQ} \mathrm{mm}$ \\
\hline
\end{tabular}

From Figure 11 it is observed that the Ultimate Tensile Strength (UTS) of specimen 1 is very less in comparison to the other two specimens. It is also observed that there is a difference between the breaking load and peak load which indicates that specimen 1 has undergone slight yielding as shown in Figure 14 when tensile force was acting on the specimen.

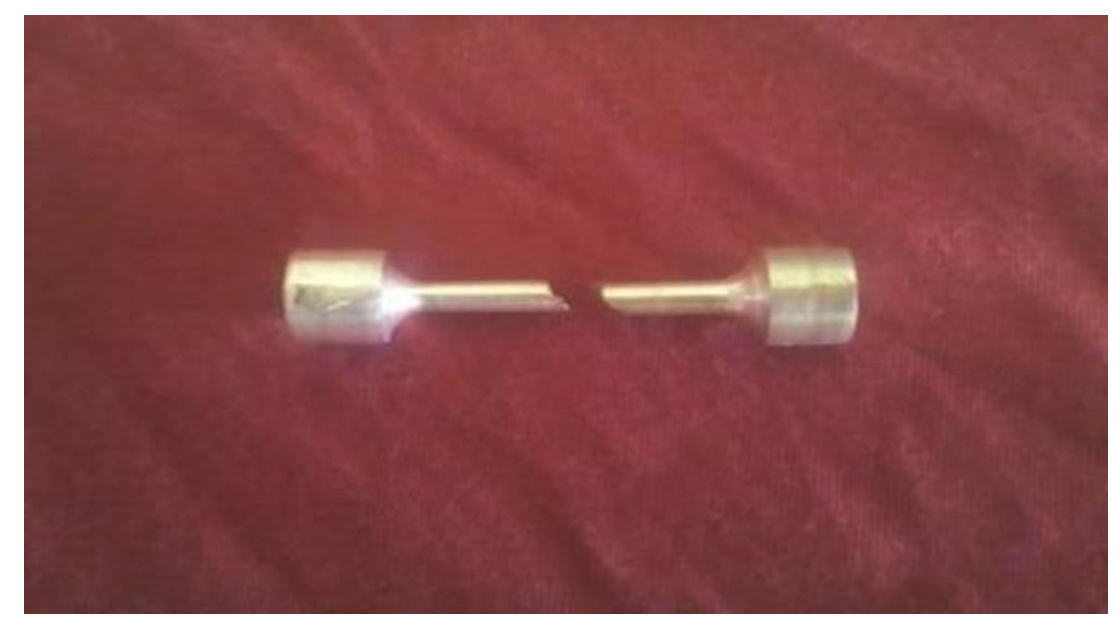

Figure 14. Fractured specimen 1 
From Figure 12 it is observed that the Ultimate Tensile Strength of specimen 2 is higher than specimen 1. It is also observed that both breaking load and peak load are equivalent which means that specimen 2 has not undergone a yielding effect concluding that specimen 2 is brittle in nature as shown in Figure 15.

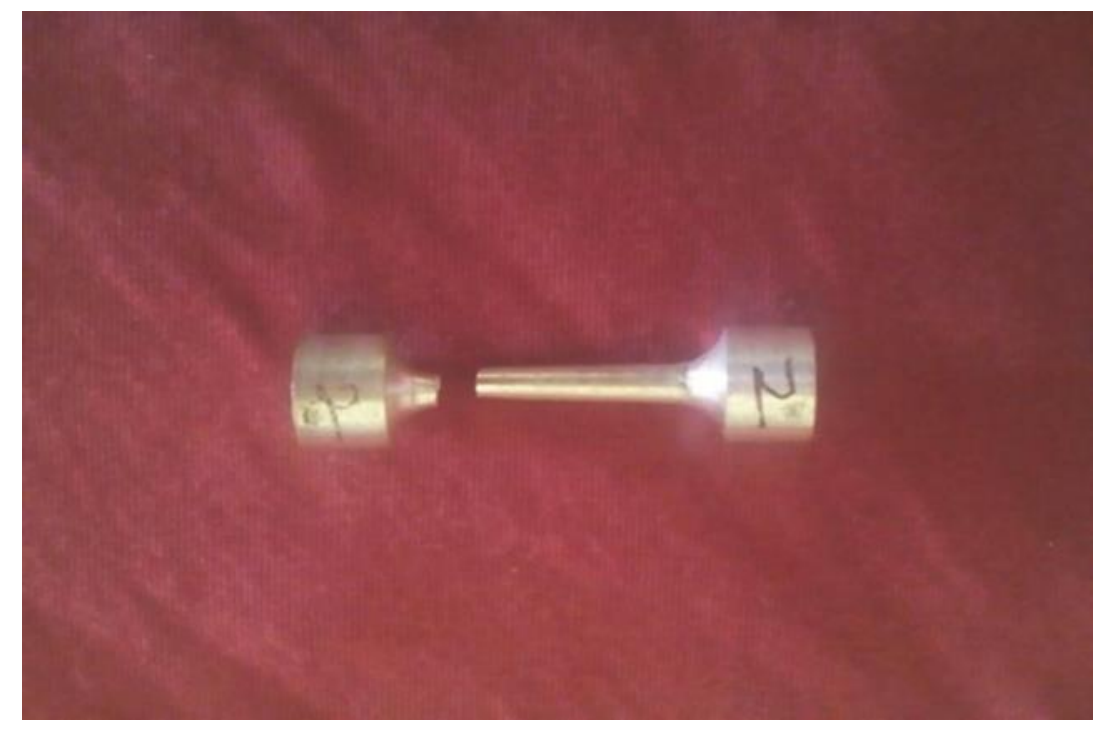

Figure 15. Fractured specimen 2

From Figure 13 it is observed that in comparison to specimen 1, specimen 3 has a higher value of Ultimate Tensile Strength due to the presence of higher aluminum content in specimen 3. It is also seen that the breaking load and peak load are equivalent which results in a non-yielding process leading to the presence of brittle behavior in specimen 3 as shown in Figure 16.

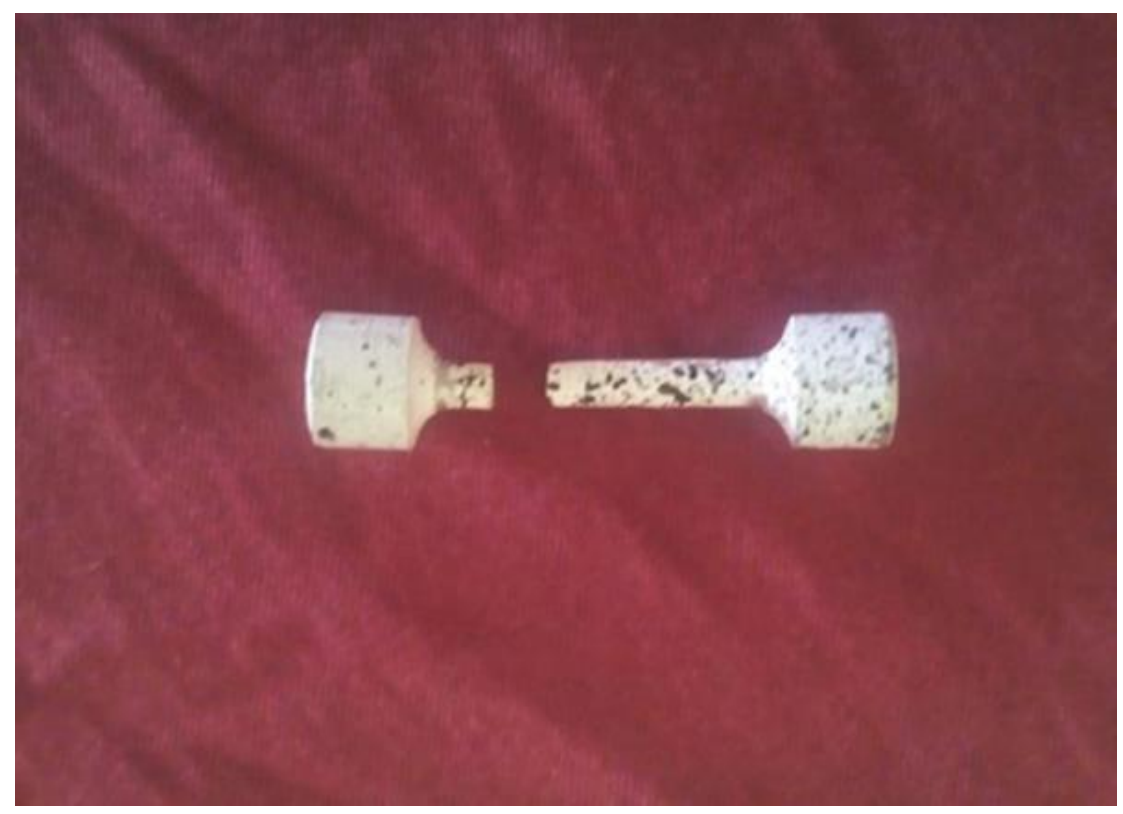

Figure 16. Fractured specimen 3 
For the Micro Vickers hardness test, the apparatus was adjusted to apply 100g force on all three specimens. The obtained results are shown in Table 5. At the position of the formation of defects such as micro holes, the hardness value will be less. It can be observed from the result that specimen 2 has a higher value in comparison to the other two specimens.

Table 5. Micro Vickers Hardness test results

\begin{tabular}{llll}
\hline $\begin{array}{l}\text { Vickers Hardness } \\
\text { Value }\end{array}$ & Specimen 1 & Specimen 2 & Specimen 3 \\
\hline Reading 1 & 57.4 & 77.7 & 51.8 \\
Reading 2 & 38.7 & 87.4 & 53.5 \\
Reading 3 & 58.2 & 53.3 & 56.5 \\
Mean Value & 51.4 & 72.8 & 53.9 \\
\hline
\end{tabular}

\section{Conclusion}

In the present research work, three specially reinforced magnesium composites samples were prepared by using the squeeze casting process Due to the incorporation of different reinforcements in the magnesium matrix, novel magnesium matrix composites have been manufactured. Specimen 2 has fewer external and internal defects so its Micro Vickers hardness value is greater than the other two specimens fabricated. It is also observed that specimen 2 has a higher value of Ultimate Tensile Strength than specimen 1 and specimen 3. From the microstructure analysis, it can be concluded that uniform distribution of reinforcement particles led to higher values of Ultimate Tensile Strength and Micro Vickers Hardness. The future research work based on this study can be based on the implementation of Machine Learning algorithms such as Artificial Neural Network, Support Vector Machines (SVM), and Decision Tree algorithm for the determination of the mechanical and microstructure properties as well as the geometrical properties analysis of the obtained microstructures by using an image processing algorithm.

\section{References}

1. Kumar, S., Singh, R. and Hashmi, M.S.J., 2020. Metal matrix composite: a methodological review. Advances in Materials and Processing Technologies, 6(1), pp.13-24.

2. Bahl, S., 2020. Fiber reinforced metal matrix composites-a review. Materials Today: Proceedings.

3. Bhoi, N.K., Singh, H. and Pratap, S., 2020. Developments in the aluminum metal matrix composites reinforced by micro/nano particles-a review. Journal of Composite Materials, 54(6), pp.813-833. 
4. Güler, Ö. and Bağc1, N., 2020. A short review on mechanical properties of graphene reinforced metal matrix composites. Journal of Materials Research and Technology, 9(3), pp.6808-6833.

5. Węglewski, W., Pitchai, P., Bochenek, K., Bolzon, G., Konetschnik, R., Sartory, B., Ebner, R., Kiener, D. and Basista, M., 2020. Experimental and Numerical Investigation of the Deformation and Fracture Mode of Microcantilever Beams Made of Cr (Re)/Al 2 O 3 MetalMatrix Composite. Metallurgical and Materials Transactions A, pp.1-14.

6. Ramesh, P. and Nataraj, M., 2020. Automotive industry application of aluminium-based hybrid metal matrix composite. International Journal of Heavy Vehicle Systems, 27(1-2), pp.18-32.

7. Pandian, V. and Kannan, S., 2020. Processing and preparation of aerospace-grade aluminium hybrid metal matrix composite in a modified stir casting furnace integrated with mechanical supersonic vibration squeeze infiltration method. Materials Today Communications, p.101732.

8. Saleh, B.I. and Ahmed, M.H., 2020. Development of functionally graded tubes based on pure Al/Al 2 O 3 metal matrix composites manufactured by centrifugal casting for automotive applications. Metals and Materials International, 26(9), pp.1430-1440.

9. Singh, H., Kumar, D. and Singh, H., 2020. Development of magnesium-based hybrid metal matrix composite through in situ micro, nano reinforcements. Journal of Composite Materials, p.0021998320946432.

10. Kumar, A., Arafath, M.Y., Gupta, P., Kumar, D., Hussain, C.M. and Jamwal, A., 2020. Microstructural and mechano-tribological behavior of $\mathrm{Al}$ reinforced SiC-TiC hybrid metal matrix composite. Materials Today: Proceedings, 21, pp.1417-1420.

11. Dinaharan, I., Zhang, S., Chen, G. and Shi, Q., 2020. Development of titanium particulate reinforced AZ31 magnesium matrix composites via friction stir processing. Journal of Alloys and Compounds, 820, p.153071.

12. Say, Y., Guler, O. and Dikici, B., 2020. Carbon nanotube (CNT) reinforced magnesium matrix composites: The effect of CNT ratio on their mechanical properties and corrosion resistance. Materials Science and Engineering: A, 798, p.139636. 